\title{
Práticas de promoção da saúde no trabalho do professor
}

Health promotion practices in teachers' work

Prácticas de promoción de la salud en el trabajo del profesor

\author{
Fabiano Oliveira Antonini ${ }^{1}$ (c) https://orcid.org/0000-0003-2139-2245 \\ Ivonete Teresinha Schülter Buss Heidemann² Đ https://orcid.org/0000-0001-6216-1633 \\ Jeane Barros de Barros de Souza ${ }^{3}$ iD https://orcid.org/0000-0002-0512-9765 \\ Michelle Kuntz Durand ${ }^{2}$ id https://orcid.org/0000-0003-3660-6859 \\ Aline Megumi Arakawa Belaunde ${ }^{2}$ id https://orcid.org/0000-0002-2159-6486 \\ Paola Margarita Onate Daza ${ }^{2,4}$ (I) https://orcid.org/0000-0002-7291-1546
}

Como citar:

Antonini FO, Heidemann IT, Souza JB, Durand MK, Belaunde AM, Daza PM. Práticas de promoção da saúde no trabalho do professor. Acta Paul Enferm.

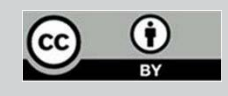

Descritores

Docentes; Educação em saúde; Promoção da saúde; Saúde

do trabalhador

Keywords

Faculty; Health education; Health promotion; Occupational

Descriptores

Docentes; Educación en salud; Promoción de la salud;

Salud labora

Submetido 25 de Setembro de 2020

Aceito

8 de Março de 202

Autor correspondente Ivonete Teresinha Schülter Buss Heideman E-mail: ivonete.heidemann@ufsc.br

Editor Associado (Avaliação pelos pares): Alexandre Pazetto Balsanel (https://orcid.org/0000-0003-3757-1061) Escola Paulista de Enfermagem, Universidade Federal de São Paulo, São Paulo, SP, Brasil

\section{Resumo}

Objetivo: Compreender as práticas de promoção da saúde do trabalhador que são realizadas pelos professores da área da saúde de uma instituição pública de ensino tecnológico.

Métodos: Pesquisa de abordagem qualitativa do tipo pesquisa ação participante, articulada com o Itinerário de Pesquisa de Paulo Freire, que consiste de três etapas que estão interligadas: investigação temática; codificação e descodificação; desvelamento crítico. Foram desenvolvidos cinco Círculos de Cultura, entre abril e junho de 2018, envolvendo a participação de 21 professores da área da saúde.

Resultados: Os professores desvelaram que as condições laborais, relacionamentos interpessoais, ambiente de trabalho e hábitos de vida são fatores que afetam a saúde do trabalhador. Percebem que a política de saúde do trabalhador não está condizente com o serviço, o qual deve ser reorganizado para maior eficiência. Apontaram práticas para promover saúde: equilíbrio entre trabalho e vida pessoal, formação de grupos de ajuda mútua e troca de conhecimento no ambiente de trabalho, lazer, preparo emocional, alimentação saudável e manter as relações interpessoais, trazendo benefícios para sua qualidade de vida.

Conclusão: Evidenciou-se a aproximação da Promoção da Saúde com a Saúde do Trabalhador, demonstrando que esta pode ser desenvolvida em diferentes cenários e participantes. As práticas que possibilitem a Promoção da Saúde podem trazer muitos benefícios para melhoria de sua qualidade de vida.

\section{Abstract}

Objective: To understand health promotion practices of workers carried out by health teachers at a public technological education institution.

Methods: This is a qualitative research of the participatory action research type, articulated with Paulo Freire's Research Itinerary, which consists of three interconnected stages: thematic research; coding and decoding; critical unveiling. Five Culture Circles were developed between April and June 2018, involving the participation of 21 health teachers.

Results: Teachers revealed that working conditions, interpersonal relationships, work environment, and lifestyle habits are factors that affect workers' health. They perceive that workers' health policy is not consistent with the service, which must be reorganized for greater efficiency. They pointed out practices to promote health: balance between work and personal life, formation of mutual help groups and exchange of knowledge in the work environment, leisure, emotional preparation, healthy eating and maintaining interpersonal relationships, bringing benefits to their quality of life.

Instituto Federal de Santa Catarina, Florianópolis, SC, Brasil.

ZUniversidade Federal de Santa Catarina, Florianópolis, SC, Brasil.

3Universidade Federal da Fronteira Sul, Chapecó, SC, Brasil.

4Universidad Popular del Cesar, Valledupar, Cesar, Colômbia.

Conflitos de interesse: nada a declarar. 
Conclusion: The approximation between health promotion and worker's health was evidenced, demonstrating that it can be developed in different settings and participants. Practices that enable health promotion can bring many benefits to improve their quality of life.

\section{Resumen}

Objetivo: Comprender las prácticas de promoción de la salud del trabajador que realizan los profesores del área de la salud de una institución pública de enseñanza tecnológica.

Métodos: Estudio de enfoque cualitativo tipo investigación-acción participante, articulado con el itinerario de investigación de Paulo Freire, que consiste en tres etapas interconectadas: investigación temática, codificación y decodificación, revelación crítica. Se desarrollaron cinco Círculos de Cultura entre abril y junio de 2018, con la participación de 21 profesores del área de la salud.

Resultados: Los profesores revelaron que las condiciones laborales, las relaciones interpersonales, el ambiente de trabajo y los hábitos de vida son factores que afectan la salud del trabajador. Percibieron que la política de salud del trabajador no se condice con el servicio, el cual debería reorganizarse para lograr mayor eficiencia. Señalaron prácticas para promover la salud: equilibrio entre trabajo y vida personal, formación de grupos de ayuda mutua e intercambio de conocimientos en el ambiente de trabajo, recreación, preparación emocional, alimentación saludable y mantener las relaciones interpersonales, que ofrecen beneficios para su calidad de vida.

Conclusión: Se evidenció la aproximación entre la promoción de la salud y la salud del trabajador, lo que demuestra que esta puede desarrollarse en diferentes escenarios y con diferentes participantes. Las prácticas que permiten la promoción de la salud pueden ofrecer muchos beneficios para mejorar la calidad de vida.

\section{Introdução}

A Promoçáo da Saúde vem sendo discutida ao longo do tempo, com o intuito de compreender maneiras de as pessoas viverem em melhores condições de vida. Considera-se os fatores além da saúde física e mental, abarcando os determinantes da saúde como trabalho, habitação, lazer, família e amigos. ${ }^{(1,2)}$ A Promoção da Saúde desenvolve-se em diversos cenários, como na Saúde do Trabalhador e no ambiente escolar, no qual esta pesquisa se realizou.

A promoção da saúde foi definida na Carta de Ottawa como "o processo que busca permitir que as pessoas aumentem o controle e a melhoria da saúde" (WHO, 1986, p. 1). ${ }^{(3)}$ Entretanto, apesar das concepçóes de promoção da saúde serem defendidas na Carta, ocorrem divergências em relação à temática. Há dois discursos diferentes: um relacionado ao modelo biológico com enfoque na doença e mudanças de estilos de vida e outro que procura reforçar a perspectiva emancipatória e estimular o empoderamento individual e coletivo que busca a autonomia das pessoas para transformar a realidade. ${ }^{(1)}$

Os locais de trabalho devem receber atenção especial. No século 21, conforme a Organização Mundial da Saúde, o local de trabalho foi estabelecido como um dos cenários prioritários para a promoção da saúde por influenciar o bem-estar físico, mental, econômico e social. $\mathrm{Na}$ área escolar tem sido evidenciado um crescimento de agravos a saúde dos professores, associados às condições e características do seu trabalho. ${ }^{(4)}$

O trabalho e suas relações com a saúde são orientados a partir de aspectos socioculturais, econômicos e produtivos, de acordo com a sociedade em que se vive. Tais relaçóes, no ambiente escolar, necessitam do entendimento dos métodos de organização do trabalho, dos profissionais da educaçáo e as condiçôes desencadeantes do processo saúde-doença. Este conhecimento fornece subsídios para a investigação dos processos laborais e as repercussóes em saúde, decorrente da interação entre o meio e o indivíduo. ${ }^{(5)}$

Diante de condiçóes sociais e de saúde que afetam os setores da população trabalhadora, é necessário ampliar estudos relacionados à promoção da saúde no ambiente laboral, ao identificar e descrever as intervençôes realizadas. ${ }^{(6)} \mathrm{Nas}$ instituiçóes de ensino emerge a promoção de açóes em prol da melhoria do trabalho educativo e na formaçáo relacionada aos cuidados de saúde, para o desenvolvimento de habilidades em busca da qualidade de vida e do viver saudável de todos os indivíduos envolvidos no cenário educacional. ${ }^{(7)}$

Diante do exposto questiona-se: Quais as práticas de promoção da saúde do trabalhador que são realizadas pelos professores da área da saúde de uma instituição pública de ensino tecnológico? A partir de então, o estudo teve como objetivo compreender as práticas de promoção da saúde do trabalhador que são realizadas pelos professores da área da saúde de uma instituição pública de ensino tecnológico. 


\section{Métodos}

Trata-se de uma pesquisa de abordagem qualitativa, do tipo pesquisa ação participante, que considera o pesquisar como um movimento pedagógico conectado à transformaçáo social, possibilitando que o estudo resulte em uma prática. ${ }^{(8)}$ Por meio do diálogo de forma horizontalizada, crítica e reflexiva, a pesquisa açáo participante promove a autonomia e o empoderamento dos sujeitos, com valorização do conhecimento científico e popular para o enfrentamento de um problema.

A pesquisa açáo participante tem como objetivo alcançar resultados socialmente relevantes e caracteriza-se pelo envolvimento do mediador e participante, sendo que o relacionamento entre pesquisador e pesquisado não ocorre com a mera observação do primeiro pelo segundo, mas identificando-se com a realidade social..$^{(8)}$

$\mathrm{O}$ estudo fundamentou-se nos pressupostos de Paulo Freire, em que percorreu-se o Itinerário de Pesquisa, composto por três etapas dialéticas, que estâo interligadas entre si: 1) investigação temática; 2) codificação e descodificação; 3) desvelamento crítico.

A investigação temática visa à identificação dos temas geradores extraídos da realidade dos participantes. A contextualização vai ocorrendo na medida em que as situaçôes são identificadas por meio do diálogo, no qual os participantes levantam as contradiçóes, as situaçóes concretas e reais em que estáo vivendo o seu aqui e agora. Na segunda etapa ocorre a contextualizaçáo e problematizaçáo dos temas geradores, tomando consciência do mundo vivido. Representa a análise da situação vivida, momento dialético em que os participantes passam a admirar e refletir sobre sua ação. $\mathrm{Na}$ terceira fase busca-se a transformação do contexto vivido. Os participantes realizam a tomada de consciência da situação vívida, em que se descobrem as fragilidades e as potencialidades da realidade. Ocorre o processo de ação-reflexão-ação que capacita os participantes a compreender e intervir sobre a realidade com o enfrentamento das contradiçōes. ${ }^{(7,9,10)}$

As etapas do Itinerário de Pesquisa de Freire ocorrem em espaços denominados de Círculos de Cultura, que consistem em uma reflexão crítica, emergindo a consciência do mundo vivido. Os participantes, por meio do diálogo, reelaboram o mundo e ao reconstruí-lo, percebem-se de que este é construído também por eles. ${ }^{(9,10)}$ Somado a isso, o Círculo de Cultura possibilita a aproximação entre pesquisadores e participantes do estudo, em que o assunto de interesse do pesquisador transforma-se em interesse coletivo por meio de uma reflexão profunda da realidade.

O estudo realizou-se em uma capital da região Sul do Brasil, em uma instituição federal de ensino profissional, científico e tecnológico, que possui 391 professores. Participaram do estudo 21 professores. Como critério de inclusão considerou-se os professores em pleno exercício da docência entre efetivos e contratados, com no mínimo dois anos de experiência no magistério na área da saúde. Como critério de exclusão foram considerados aqueles afastados por férias ou licença de qualquer natureza no período de desenvolvimento do estudo.

Foram realizados quatro Círculos de Cultura que ocorreram nas dependências da instituição de ensino, entre abril e junho de 2018. Durante os encontros o ambiente foi disposto em roda e os diálogos foram gravados em vídeo, sendo posteriormente transcritos de maneira direcionada.

Os Círculos de Cultura foram organizados quinzenalmente, com tempo de duraçáo de uma hora e meia cada. O primeiro Círculo destinou-se a percorrer a fase da investigação temática do Itinerário de Pesquisa de Freire, em que o grupo foi encorajado a dialogar, sendo instigados por meio de duas questôes norteadoras: Quais os fatores relacionados ao seu trabalho que podem trazer prejuízos a sua saúde? Quais práticas de promoção da saúde você desenvolve no seu ambiente de trabalho? Nesse momento, os participantes foram divididos em duplas para propiciar discussão e após, socializaram para o grande grupo as suas reflexôes.

No segundo Círculo de Cultura desenvolveu-se a etapa da codificação e descodificação, em que buscou-se os significados e compreensão dos temas levantados pelo grupo no encontro anterior, tendo como referencial teórico a promoção da saúde e a saúde do trabalhador para mediar os diálogos. Em to- 
dos os Círculos de Cultura foram debatidos os temas geradores que foram investigados, codificados e descodificados pelo grupo, registrados na lousa, classificados e agrupados por proximidades e semelhanças das temáticas. Oito temas envolveram a Promoção da Saúde e quatro a Saúde no Trabalho, impulsionando a comunicação nos demais Círculos de Cultura.

No terceiro e quarto Círculo de Cultura foi realizada uma síntese dos temas geradores, que foram codificados e descodificados. Nestes dois últimos Círculos os participantes fizeram um sorteio de um tema aleatoriamente, expondo sua opinião com a interferência e discussão, procurando destacar as práticas promotoras de saúde. Por meio do processo de ação-reflexão-ação e tomada de consciência da realidade vivenciada, os professores puderam compreender e se motivar a promover sua saúde no seu espaço laboral.

O desvelamento crítico ocorreu desde o primeiro encontro, quando os participantes, durante as discussóes, tomaram consciência de sua realidade e expressaram açóes e práticas para transformar sua realidade e promover saúde. Por ser uma pesquisa de cunho participativo, a análise dos temas ocorreu de acordo com o que emergiu nos Círculos de Cultura e concomitante ao seu desenvolvimento.

O estudo foi realizado de acordo com os princípios éticos que constam na Resolução 466/2012 do Conselho Nacional de Saúde, iniciando-se após aprovação do Comitê de Ética em Pesquisa com Seres Humanos, sobre o CAAE número 80121317.4.0000.0121. Para a garantia do anonimato os participantes foram denominados por codinomes por eles aleatoriamente eleitos.

\section{Resultados}

Os 21 participantes do estudo atuavam como professores nos cursos da área da saúde, sendo: Técnico em Enfermagem, Tecnólogo em Radiologia, Mestrado Profissional em Proteção Radiológica, Curso de Formação Inicial e Continuada em Cuidadores de idosos, Recepcionista de serviços de saúde. A maioria dos participantes era do sexo feminino $(72 \%)$, casados (62\%), com idade entre 25 a 50 anos. Quanto à titulação, destaca-se a Enfermagem com 52\%, se- guida por 33\% de Tecnólogos em Radiologia, 10\% de Físicos e 05\% de Engenheiros, sendo que os professores eram: especialistas (09\%), mestres (43\%) e doutores (48\%). O tempo de exercício na docência variou de dois a 28 anos, mas a maioria (53\%) tinha mais de dez anos de experiência. No primeiro Círculo de Cultura foram levantados 35 temas, sendo codificados e descodificados 12 e destes, dois foram trabalhados no desvelamento crítico: Promoção da Saúde e Saúde no Trabalho (Quadro 1).

Quadro 1. Investigação temática dos temas geradores e Codificação e Descodificação dos temas investigados

\begin{tabular}{|c|c|c|}
\hline Temas geradores & $\begin{array}{l}\text { Codificação e } \\
\text { Descodificação }\end{array}$ & $\begin{array}{l}\text { Desvelamento } \\
\text { crítico }\end{array}$ \\
\hline Equilíbrio entre trabalho e vida pessoal & \multirow{3}{*}{$\begin{array}{l}\text { Equilíbrio entre } \\
\text { trabalho e vida } \\
\text { pessoal }\end{array}$} & \multirow{20}{*}{$\begin{array}{l}\text { Promoção da } \\
\text { Saúde }\end{array}$} \\
\hline Levar trabalho para casa & & \\
\hline Tempo individual & & \\
\hline Formação de grupos de e ajuda mútua & \multirow{2}{*}{$\begin{array}{l}\text { Formação de } \\
\text { grupos de ajuda } \\
\text { mútua }\end{array}$} & \\
\hline Troca de conhecimento & & \\
\hline Práticas de atividades físicas & \multirow{6}{*}{$\begin{array}{l}\text { Práticas de } \\
\text { atividades físicas }\end{array}$} & \\
\hline Meditação & & \\
\hline Pilates & & \\
\hline Dança & & \\
\hline Futebol no campus & & \\
\hline $\begin{array}{l}\text { Culto ao corpo com exigências e cobranças que } \\
\text { trazem estresse }\end{array}$ & & \\
\hline Alimentação saudável & $\begin{array}{l}\text { Alimentação } \\
\text { saudável }\end{array}$ & \\
\hline Redução de danos através de válvulas de escape & \multirow{2}{*}{$\begin{array}{l}\text { Redução de danos } \\
\text { através de válvulas } \\
\text { de escape }\end{array}$} & \\
\hline Lazer para evitar o estresse & & \\
\hline Bom relacionamento social & \multirow{2}{*}{$\begin{array}{l}\text { Bom } \\
\text { relacionamento } \\
\text { social }\end{array}$} & \\
\hline Preparo emocional para relações interpessoais & & \\
\hline Sensibilizar e se permitir práticas de saúde & \multirow{2}{*}{$\begin{array}{l}\text { Sensibilizar e se } \\
\text { permitir práticas de } \\
\text { saúde }\end{array}$} & \\
\hline Empoderamento individual & & \\
\hline Ergonomia & \multirow{2}{*}{$\begin{array}{l}\text { Ambiente de trabalho } \\
\text { e ergonomia }\end{array}$} & \\
\hline Ambiente de trabalho & & \\
\hline Pressão do trabalho & \multirow[t]{5}{*}{ Pressão do trabalho } & \multirow{15}{*}{$\begin{array}{l}\text { Saúde no } \\
\text { Trabalho }\end{array}$} \\
\hline $\begin{array}{l}\text { Impacto das políticas educacionais, e processos } \\
\text { pedagógicos e burocráticos }\end{array}$ & & \\
\hline Cobranças de produtividade & & \\
\hline Pressão psicológica sobre servidores federais & & \\
\hline $\begin{array}{l}\text { Afastamento de colegas por motivos de saúde e } \\
\text { sobrecarga de trabalho para quem substitui }\end{array}$ & & \\
\hline $\begin{array}{l}\text { Relações de trabalho entre alunos, colegas e } \\
\text { chefia }\end{array}$ & \multirow{2}{*}{$\begin{array}{l}\text { Relações de } \\
\text { trabalho entre } \\
\text { alunos, colegas e } \\
\text { chefia }\end{array}$} & \\
\hline Conduta em sala de aula entre alunos e professor & & \\
\hline Falta de capacitação para docência & \multirow{2}{*}{$\begin{array}{l}\text { Falta de } \\
\text { capacitação para } \\
\text { docência }\end{array}$} & \\
\hline Planejamento de atividades & & \\
\hline Desvalorização do professor & \multirow{6}{*}{$\begin{array}{l}\text { Desvalorização do } \\
\text { professor }\end{array}$} & \\
\hline Sentimento de ser descartável & & \\
\hline Só dá aula & & \\
\hline Mídia de desvalorização do serviço público & & \\
\hline Desmonte do serviço público & & \\
\hline Sentimento de trabalhar muito, mas não produtivo & & \\
\hline
\end{tabular}




\section{Promoção da Saúde}

Dentro da temática da promoção da saúde, 35 temas foram investigados, que por agrupamento e significância foram codificados e descodificados, emergindo oito temas mais relevantes.

Os participantes foram unânimes em afirmar que o equilíbrio entre trabalho e vida pessoal é um fator que interfere na sua promoção da saúde, apontando que não conseguem tal equilíbrio e por vezes, levam trabalho para casa:

"A gente tem que achar um equilibrio entre trabatho e vida pessoal, que a gente nunca sabe aonde está este limite." (Grama)

"Que linha é essa que separa o pessoal do profissional, que a gente não consegue fazer isso e o trabatho vai junto para casa." (Esperança)

Os professores desvelaram que as condiçōes de trabalho são fatores que contribuem para reproduzir esta situação. Durante o transcorrer dos Círculos de Cultura debateram que é relevante a formação de grupos de ajuda mútua para troca de conhecimento no ambiente de trabalho para evitar o estresse, ter preparo emocional e bom relacionamento social para manter as relaçóes interpessoais:

"O que a gente poderia fazer para melhorar a saúde do trabalhador, é ter um grupo entre nós para discutir e refletir." (Roling Stones)

O ambiente de trabalho e a ergonomia podem contribuir para o adoecimento dos professores. Desvelaram que podem promover sua saúde por meio da criação de ambientes favoráveis de trabalho. Os ambientes de trabalho, por apresentarem riscos à saúde dos trabalhadores, devem receber atenção para minimizar os mesmos, aspecto reconhecido pelos participantes que identificaram como riscos o arranjo físico, transporte de cargas, ruído, temperatura, exposição a materiais biológicos, exposição a radiaçôes ionizantes, e acidentes. Destacam que a instituição proporciona mecanismos para promover a saúde do trabalhador, mas é necessário avançar neste tema:
Os professores identificaram a necessidade de reorientar os serviços de saúde do trabalhador existente na instituição, refletindo que existem ações promotoras de saúde que ultrapassam as obrigatórias por lei. No entanto, sugeriram aprimoramento em prol da eficiência:

"Existe a politica de Saúde do Trabalhador, só que o serviço deve ser reorganizado, para ser mais eficiente." (Cravo)

A alimentação saudável foi dialogada em várias oportunidades como uma prática de promoção da saúde. Discutiu-se sobre os alimentos da cantina da instituição e sugerido a alteração do edital de prestação deste serviço, para que obrigatoriamente seja oferecido a opção de alimentos mais saudáveis.

Os professores conseguem relacionar a alimentação saudável como uma prática promotora de saúde, reconhecem os benefícios, procurando realizá-la:

"Teoricamente na licitação da cantina tem que oferecer três opçóes de alimentos integrais[...] só que a aparência é tão feia." (Luna)

"Sugerir que eles (cantina) ampliassem os alimentos saudáveis da concorrência de preço[...] Estou esperando o próximo edital para sugerir esta alteração." (Bread)

Os professores destacaram que a instituição proporciona alguns espaços para algumas práticas promotoras de saúde como atividades físicas e meditação. Mas se sentem desconfortáveis em realizá-las por receio do que os colegas de trabalho possam pensar a respeito:

"Tem meditação no campus, tem pilates duas vezes por semana[...] mas se alguém vê[...] há tem tempo para isso[...] na hora do trabalho." (Azul)

No desenvolvimento da pesquisa, alguns professores retornaram a práticas de atividades físicas ou pelo menos se organizaram para realizá-las. $\mathrm{Na}$ avaliação final dos Círculos de Cultura houve um destaque para o benefício deste trabalho em motivar a prática de atividade física. 


\section{Saúde no trabalho}

Durante os diálogos abordaram-se questôes com forte relação à pressão do trabalho, cobranças de produtividade, pressão psicológica sobre servidores federais, a mídia de desvalorizaçáo e desmonte do serviço público, o impacto das políticas educacionais, processos pedagógicos e burocráticos, as relaçôes de trabalho entre alunos, colegas e chefia, a desvalorizaçáo profissional, sentimento de ser descartável como questôes que permeiam o cotidiano dos professores, dificultando atender as necessidades de cada estudante:

"O trabalho docente, onde o aumento da produtividade e cobranças tem impacto na Saúde do Trabalhador[...] também o impacto das novas politicas educacionais implantadas e o docente não está preparado para isso." (Mandala)

"A desvalorização do professor, principalmente os alunos não te respeitam [...] qu que leva a desmotivação." (Gab)

"Nós não temos preparo, isso angustia porque eu quero fazer o melhor para aquele aluno que apresenta alguma dificuldade, como portador de necessidades especiais, e eu como professor tenho que dar um jeito." (Esperança)

"Uma das dificuldades é saber individualizar o aluno[...]mas ao mesmo tempo ele faz parte de um geral que não posso tratar diferente[...] ce como atender as necessidades dele?" (Grama)

Os professores codificaram e descodificaram que o impacto das políticas educacionais, processos pedagógicos e burocráticos podem interferir positivamente e negativamente na saúde do trabalhador. Desvelaram que existem políticas públicas relacionadas à saúde do trabalhador na esfera federal e institucional, mas apresentam falhas de execução, muitas vezes ocorrendo programas pontuais e sem continuidade (necessitando ênfase na capacitação dos professores para auxiliar no planejamento de atividades), relacionados a iniciativas de professores, conforme o seu interesse:
"Há dois anos, mais ou menos, foi criado um setor de Saúde do Trabalhador Federal[...]mas não tem controle." (Luna)

"Eu já tive uma experiência bem diferente, estive afastada e fui para perícia [...] o médico foi extremamente grosseiro[...] só fui atendida vinte dias após meu retorno." (Coração)

Por fim, é possível inferir que o aumento de atribuiçôes dos professores no contexto atual, as condições de trabalho e a desarticulação com as políticas proporcionam o adoecimento físico e mental, implicando no sofrimento e aumento do absenteísmo, decorrentes da administração do trabalho e promoção de saúde insatisfatórias.

\section{Discussão}

O equilíbrio entre trabalho e vida pessoal está atrelado à carga física, emocional, excesso de trabalho administrativo e atividades burocráticas, bem como com as condições inadequadas de trabalho que os professores estáo expostos. O desequilíbrio destas condições afeta o bem-estar e até mesmo a qualidade do trabalho. ${ }^{(7)}$

O estresse ocupacional, vivenciado pelo docente está relacionado a sobrecarga de trabalho, a falta de controle sobre o tempo, os problemas comportamentais dos estudantes, a burocracia excessiva, a implementação de novas iniciativas educacionais e a dificuldade de relacionamento com os supervisores como sendo os principais fatores de desgaste no trabalho. ${ }^{(7,9)}$

Momentos de diálogo em grupos podem amenizar o estresse vivenciado dado que o grupo em si é uma potente ferramenta na produçáo do cuidado, ao se apresentar como um espaço para compartilhamento de saberes, técnicos e populares e, também, local de acolhimento e formação de redes comunitárias. ${ }^{(11)}$ São os encontros em grupo que promovem a socialização, mudanças nos hábitos de vida e aprendizagem, atentando-se ao fato de náo bastar apenas reunir as pessoas em um agrupamento, mas fortalecer as relaçōes interpessoais e proporcionar 
um permanente processo de reciprocidade entre os participantes, podendo ser uma ferramenta transformadora na busca por mudanças de comportamento e estratégias de enfrentamento. ${ }^{(12)}$

Os agentes ambientais nocivos no trabalho do professor são o ruído, a poeira, a temperatura e a iluminação inadequada. Nas legislaçôes há maior ênfase no modelo curativo em detrimento da promoção de saúde do professor. ${ }^{(13)}$ As práticas de promoção de saúde, visando a preocupação coletiva no trabalho, diminuem o estresse ocupacional. Além disso, articular pesquisa e trabalho otimiza as condiçôes laborais, sendo que as intervençôes dialógicas em grupo refletem na mudança de hábitos e as melhores condiçôes de trabalho. ${ }^{(12)}$

Os professores fazem poucas atividades físicas, o que reforça a hipótese de que a atual estrutura de trabalho docente pode dificultar a sua prática no tempo livre, sendo necessário considerar as açóes de promoção da saúde, no que tange essa prática. ${ }^{(14)}$

As estratégias de promoção da saúde, relatadas pelos participantes, estão alinhadas aos princípios propostos na Carta de Ottawa ${ }^{(3)}$ e de acordo com os temas prioritários da Política Nacional de Promoção da Saúde, como formação e educação permanente, alimentação adequada e saudável, práticas corporais e atividades físicas. ${ }^{(15)}$

Os aspectos contextuais do cotidiano dos professores trazem agravos à sua saúde. Tal situação está relacionada ao excesso de tarefas e dificuldades de relacionamento, aumento da carga ocupacional, demanda por índices institucionais elevados, alta pressão por desempenho e baixo nível de controle das tarefas, ruídos, hostilidade entre estudantes, desvalorização pessoal e salarial, problemas institucionais e infraestrutura escolar inadequada para o trabalho. ${ }^{(13)}$

Ao considerar a somatória dos fatores apontados como dificultosos na condução do seu trabalho, o professor vivencia momentos de esforço físico, emocional e estresse. Neste contexto, a válvula de escape pode vir por meio da realização de atividades de lazer no ambiente de trabalho e fora dele, visto que contribuem para redução de danos. A ausência desta, associada às demandas cotidianas, pode levar o profissional a ter problemas de saúde com ênfase na saúde mental. ${ }^{(16)}$
Faz-se necessário considerar a presença da naturalização da problemática do mal-estar e adoecimentos envolvido com o ser ou estar professor, frente às dificuldades na percepção do processo de saúde-doença no trabalho e demora na busca de serviços de atenção à saúde. A promoção da saúde deve estar envolvida na cultura docente ao evitar o negligenciamento do bem-estar na organização do trabalho escolar. $^{(17)}$

A causa frequente de absenteísmo para tratamento de saúde dos professores são os transtornos psiquiátricos, com origem em vários fatores: relações interpessoais; insatisfação com o trabalho e deterioração das condiçôes laborais; imagem do trabalhador do serviço público; responsabilização pelas deficiências dos serviços, por possíveis crises das instituições públicas; acúmulo de funçôes e a má gerência na organização do trabalho; modelo de gestão altamente hierarquizado e tomado pela burocracia; estereótipo do servidor público federal caracterizado pela morosidade. Neste sentido, sugere-se implantar medidas de promoção e prevenção da saúde nos locais de trabalho, com vistas a favorecer a saúde dos trabalhadores e reduzir as taxas de absenteísmo. ${ }^{(18)}$

Tais fatores sinalizam para as demandas dos professores frente ao seu cuidado em saúde e aos aspectos que podem ser desenvolvidos por uma rede que priorize ações de atenção à saúde do trabalhador, em detrimento da medicina curativista. Somente o envolvimento da gestão da saúde do professor é insuficiente para resolver a questáo, uma vez que o contexto educacional se apresenta como espaço adoecido, sendo essencial que seja reestruturado com o entrelaçamento entre as políticas de saúde e de educação. ${ }^{(19)}$

Como limitaçóes deste estudo cita-se o número restrito de pesquisas atuais relacionadas à temática de promoção da saúde no trabalho dos professores e a dificuldade de reunir os participantes para o desenvolvimento dos Círculos de Cultura, em decorrências das características da atividade docente.

\section{Conclusão}

No desenvolvimento desta pesquisa foi evidente a interligação entre a Promoção da Saúde e a Saúde 
do Trabalhador. Os professores identificaram que as condiçóes de trabalho e relacionamentos interpessoais são fatores que afetam o seu bem-estar, da mesma forma que o ambiente de trabalho e hábitos de vida possibilitam a Promoção da Saúde, repercutindo na melhoria da sua qualidade de vida. Desvelaram que existe uma política para a Saúde do Trabalhador, tanto na esfera federal como institucional, mas necessita de uma reorientação dos serviços prestados. Durante os diálogos nos Círculos de Cultura, algumas práticas destacaram-se: busca pelo equilíbrio entre trabalho e vida pessoal; formação de grupos de ajuda mútua e troca de conhecimento no ambiente de trabalho; redução de danos por meio de lazer para evitar o estresse; ter preparo emocional; bom relacionamento social para manter as relaçóes interpessoais; e alimentação saudável. A escolha do método foi positiva para direcionar os Círculos de Cultura, que por meio do diálogo, temas sensíveis foram desvelados. A pesquisa trouxe contribuições para a Promoçáo da Saúde dos professores, no momento em que desvelaram a sua realidade vivida. Espera-se que os participantes possam ser estimulados a refletir sobre sua prática e desenvolver as sugestôes que emergiram durante os Círculos, promovendo sua saúde.

\section{Colaborações}

Antonini FO, Heidemann ITSB, Souza JBB, Durand MK, Belaunde AMA e Daza PMO colaboraram com a concepção do estudo, análise e interpretação dos dados, redação do artigo, revisão crítica relevante do conteúdo intelectual e aprovaçáo da versão final a ser publicada.

\section{Referências}

1. Magalhães R. Avaliação da Política Nacional de Promoção da Saúde: perspectivas e desafios. Ciênc Saúde Coletiva. 2016;21(6):1767-75.

2. Pettres $A A$, Ros MA. A determinação social da saúde e a promoção da saúde. ACM Arq Catarin Med. 2018;47(3):201-8.
3. Brasil. Ministério da Saúde. Carta de Ottawa. Primeira Conferência Internacional sobre promoção da saúde. Brasília (DF): Ministério da Saúde; 2021 [citado 2020 Fev 21]. Disponível em: https://bvsms. saude.gov.br/bvs/publicacoes/carta_ottawa.pdf

4. Carrer P, Wolkoff P. Assessment of Indoor Air Quality Problems in Office-Like Environments: Role of Occupational Health Services. Int J Environ Res Public Health. 2018;15(4):741. Review.

5. D'Oliveira CA, Souza NV, Varella TC, Vargens OM, Noronha I, Noronha I. Teaching work routine: challenges to nursing professors in contemporary times. Rev Esc Enferm USP. 2020;54:e03577.

6. Bazzani LC, Sánchez Al. Workplace Health Promotion: a path to follow. Cien Saude Colet. 2016;21(6):1909-20. Review.

7. Antonini FO, Heideman IT. Paulo Freire's research itinerary: contributions for promoting health in the teaching profession. Rev Bras Enferm. 2020;73(4):e20190164.

8. Felcher CD, Ferreira AL, Folmer V. Da pesquisa-ação à pesquisa participante: discussões a partir de uma investigação desenvolvida no facebook. Experiênc Ensino Ciênc. 2017;12(7):1-18.

9. Heidemann IT, Dalmolin IS, Rumor PC, Cypriano CC, Costa MF, Durand MK. Reflections on Paulo Freire's research itinerary: contributions to health. Texto Contexto Enferm. 2017;26(4):e0680017.

10. Durand MK, Heideman IT. Social determinants of a Quilombola Community and its interface with Health Promotion. Rev Esc Enferm USP. 2019;53:e03451.

11. Nogueira A, Munari DB, Fortuna CM, Santos LF. Leads for potentializing groups in Primary Health Care. Rev Bras Enferm. 2016;69(5):907-21.

12. Santos LF, Oliveira LM, Barbosa MA, Minamisava R, Souza BN, Nunes DP. Participation in group as a resource for health promotion and quality of life among older people. Rev Baiana Enferm. 2017;31(2):e17868.

13. Cortez PA, Souza MV, Amaral LO, Silva LC. A saúde docente no trabalho: apontamentos a partir da literatura recente. Cad Saúde Colet. 2017;25(1):113-22.

14. Dias DF, Loch MR, González AD, Andrade SM, Mesas AE. Insufficient free-time physical activity and occupational factors in Brazilian public school teachers. Rev Saúde Pública. 2017;51:68.

15. Brasil. Ministério da Saúde. Secretaria de Vigilância em Saúde. Secretaria de Atenção à Saúde. Política Nacional de Promoção da Saúde (PNPS). Brasília (DF): Ministério da Saúde; 2014 [citado 2021 Fev 21]. Disponível em: http://bvsms.saude.gov.br/bvs/publicacoes/ pnps_revisao_portaria_687.pdf

16. Dias BV, Silva PS. Síndrome de Burnout em docentes: revisão integrativa sobre as causas. Cuid Enferm. 2020;14(1)95-100.

17. Penteado RZ, Souza Neto S. Teacher malaise, suffering and sickness: From narratives of teacher work and culture to teaching as a profession. Saúde Soc São Paulo. 2019;28(1):135-53.

18. Baasch D, Trevisan RL, Cruz RM. Epidemiological profile of Santa Catarina's public servants away from work due to mental disorders from 2010 to 2013. Cienc Saude Coletiva. 2017;22(5):1641-9.

19. Santana FA, Neves IR. Saúde do trabalhador em educação: a gestão da saúde de professores de escolas públicas brasileiras. 2017;26(3):78697. 